\title{
RESEARCH ON FAULT IDENTIFICATION OF POWER EQUIPMENT BASED ON BP NEURAL NETWORK
}

\author{
Yongxiang Li ${ }^{1 *}$ Tianzheng Wang ${ }^{1}$, Gang Yang ${ }^{1}$, Hui Yuan ${ }^{1}$, Dawei Wang ${ }^{1}$ \\ ${ }^{1}$ State Grid Shanxi Electric Power Research Institute of SEPC, Shanxi, China \\ Email:y7x4f4@126.com
}

\begin{abstract}
Since the tenth five-year plan, grid-connected wind power has been developing rapidly in Inner Mongolia, Hebei, and Liaoning, easing local residents' pressure to use electricity. But the frequent failure of the gearbox of wind turbines restricts the development of wind power construction. Based on this, this study applied Back Propagation (BP) neural network technology applied to the diagnosis of wind turbine gearbox faults. The number of nodes in each layer was determined. The simulation was carried out using the MATLAB software. The results showed that the identification accuracy reached $96.5 \%$ and $95.2 \%$ respectively in wear fault gears and rolling bearing fault identification tests. The identification results verify the feasibility of the BP neural network for fault identification of power equipment. This study provides a guarantee for solving the problem of gearbox failure in wind turbines.
\end{abstract}

Keywords: Power Equipment, BP Neural Network, Fault Identification.

\section{Introduction}

With the development of wind power generation in China, the number of wind turbines (fans) increases rapidly. However, the relatively backward fault diagnosis system leads to the high maintenance cost of domestic wind turbines and serious economic losses [1-6]. Therefore, the fault identification technology of fan gearbox with high robustness is of great practical significance to the fault elimination and maintenance of fan gearbox [7-9]. To reduce the difficulty of fault diagnosis and improve the efficiency of diagnosis, this study applied the Back Propagation (BP) neural network technology into the fault diagnosis of a fan gearbox. The fault type mapping and fault diagnosis of wind turbine gearbox are completed timely, which provides a basis for eliminating faults and maintaining the gearbox of wind turbines.

\section{Overview of BP Neural Network Algorithm}

\subsection{BP Neural Network Model}

In 1986, Rumelhart et al. proposed the BP algorithm. In this algorithm, the estimated output value is calculated backward by the neural network input value, and the calculated input value is compared with the original input value to obtain the error [10]. If the error is large, then the connection weight is re-selected for calculation until the error meets the requirements. This method has a strong practical value, mainly because it solves the problem that the hidden layer is not easy to determine.

Figure 1 shows the structure diagram of the BP neural network. BP neural network has three levels: input layer, hidden layer, and output layer. $x_{1}, x_{2}, \cdots, x_{M}$ is the input value of the neural network input layer, $h_{1}, h_{2}, \cdots, h_{Q}$ is the input value of the neural network hidden layer, and $y_{1}, y_{2}, \cdots y_{L}$ is the output value of the neural network. The connection weight coefficient between the input layer and the hidden layer is $w_{j i}^{1}$; the connection weight coefficient between the hidden layer and the output layer is $w_{i j}^{2}$, and the activation function of the hidden layer and the output layer are $f(x)$ and $g(x)$, respectively.

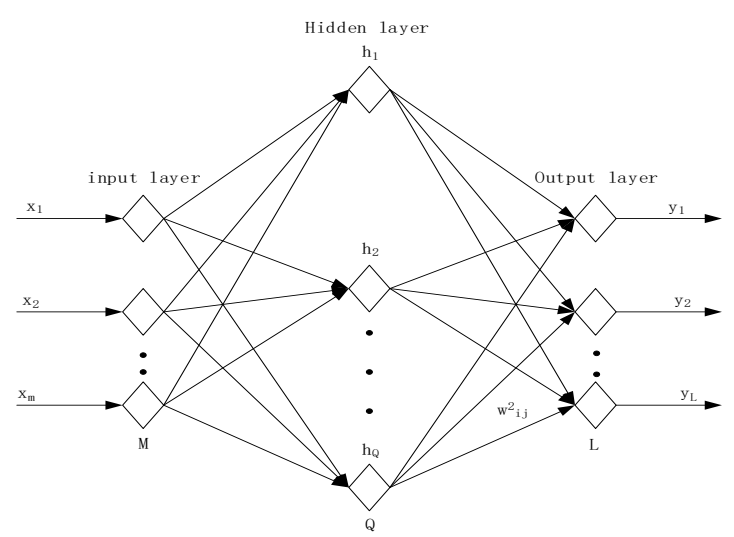

Figure 1: The Structure Diagram of A BP Neural Network 
To facilitate subsequent calculations, this article gives the input values of the input layer and the hidden layer, as shown in (1) and (2), respectively. The output values of the hidden layer and the input layer are also given, as shown in (3) and (4), respectively.

$$
\begin{aligned}
& x_{i}=x_{i}^{0} \\
& h_{j}^{1}=\sum_{i=1}^{M} w_{j i}^{1} x_{i} \\
& x_{j}^{1}=f\left(h_{j}^{1}\right) \\
& y_{l}^{2}=g\left(\sum_{j=1}^{Q} w_{i j}^{2} x_{j}^{1}\right)
\end{aligned}
$$

\subsection{Principle of BP Neural Network}

Assuming that the neural network has L layers and $\mathrm{n}$ nodes, the units of each layer only accept the information passed from the previous layer and pass the information to the units of the next layer, and the excitation function characteristics of all units are Sigmoid functions. Let $\left(x_{k}, y_{k}\right),(k=1,2, \cdots N)$ be a given, $O_{i}$ is the output of node i, $x_{k}$ is an arbitrary input value, $y_{k}$ is the output of the network, $O_{i k}$ is the output of node $i$, and the input of the j-th unit in the first layer. The input of node $\mathrm{j}$ for $\mathrm{k}$ samples is:

$$
\begin{aligned}
& n e t_{j k}^{l}=\sum w_{i j}^{l} O_{j k}^{l-1} \\
& O_{j k}^{l}=f\left(n e t_{j k}^{l}\right)
\end{aligned}
$$

where $O_{j k}^{l}$ is the output of the $\mathrm{j}$-th cell node when the k-th sample is input at layer $l-1$. The calculation steps of the BP neural network are as follows: first, the initial value of the weight coefficient is determined; second, steps (1)-(3) are repeated until the error satisfies (7).

$$
E=\frac{1}{2 N} \sum_{k=1}^{N} E_{K}<\varepsilon
$$

where A stands for precision.

(1) The forward calculation process of $k$ value $1-n$ is as follows: $O_{j k}^{l-1}, n e t_{j k}^{l}, \bar{y}_{k}$ and $k=2, \cdots, N$ of each layer unit are calculated. The reverse calculation process is that $\delta_{j k}^{l}$ is calculated for each unit of each layer.

(2) The weight is modified:

$$
w_{i j}=w_{i j}-\mu \frac{\partial E}{\partial w_{i j}}, \mu>0
$$

where A represents the step size, $\frac{\partial E}{\partial w_{i j}}=\sum_{k=1}^{N} \frac{\partial E_{k}}{\partial w_{i j}}$.

(3) The calculation stops.

\section{Construction and Realization of Fault Identification Model of Wind Turbine Gearbox}

\subsection{Determination of the Number of Nodes in Each Layer}

(1) Number of nodes in the input layer

If the BP neural network selects too many input nodes, it will increase the complexity of the network and introduce more noise. If few input nodes are selected, the information provided for the BP neural network will be missing. To avoid the noise caused by too many input nodes and the information missing caused by the insufficient number of nodes, it is of great significance to select the appropriate input node. Since the gearbox studied in this paper has eight characteristic parameters, the number of nodes in the input layer is set as eight. After that, the validity of the data needs to be determined to eliminate the false data.

(2) Number of nodes in the output layer

The number of output feature vectors in the BP neural network determines the number of nodes in the output layer. In fault diagnosis, it is best to directly output the type of gearbox fault after processing by the BP neural network; therefore, binary encoding is chosen for the output as a diagnostic rule. The four binary state codes of the rolling bearing in the gearbox and the four binary state codes of the gear are used as the output of the neural network. Among them, the four state codes of rolling bearing are normal state $(0,0,0)$, ball fault $(0,0,1)$, inner ring fault $(0,1,0)$, and outer ring fault $(1,0,0)$. The four state codes of gears are normal state $(1,0,0)$, wear fault $(0,0,1)$, broken tooth fault $(0,1,0)$, and pitting fault $(0,0,1)$. Through analysis, it can be known that only four output nodes are needed to diagnose the rolling bearing and gear faults of the gearbox; therefore, the number of nodes in output layer of the BP neural network is set as four.

(3) Number of hidden layers and hidden layer nodes

Through analysis, it can be known that continuous functions can be mapped with the BP network with single hidden layer, and for discontinuous functions, a double-hidden layer BP network is needed. Therefore, in general, the number of hidden layers of a BP network is no more than two. Through a lot of research and practice, it is shown that the first hidden layer has more nodes than the second hidden layer, which can improve the performance of the multi-layer feedforward network. 
The number of hidden layer nodes is not as large as possible. If the number of hidden layer nodes is too large, it will reduce the generalization ability of the network and increase unnecessary training time. If the number of hidden layer nodes is too small, it will not get all valid information. In this paper, the number of input layer nodes set as eight, which is $\mathrm{n}-8$, and the number of output layer nodes is set as 4, which is 1-4. After comprehensive consideration, the number of hidden layer nodes is set as 16 . The structure of the neural network is 8-16-4 three-layer. The s-type tangent function tansig and logarithmic function Purelin are selected for the activation functions of neurons in the hidden layer and output layer of the neural network.

\subsection{MATLAB Implementation of BP Neural Network}

To build the BP neural network, the newFF function in MATLAB neural network toolbox can be called to achieve. The specific invocation method is:

$$
n e t=n e w f f\left(\begin{array}{l}
P, T,[S 1, S 2 \cdots S i \cdots S(N-1)], \\
\{T F 1, T F 2 \cdots T F i \cdots T F(N-1)\}, \\
B T F, B L F, P F
\end{array}\right)
$$

In the above equation, $\mathrm{P}$ represents the input sample, $\mathrm{T}$ represents the expected response, $\mathrm{Si}$ represents the number of neurons in the layer $i$ network, TFi represents the transfer function of the layer i network, and the transfer function of the hidden layer is the tansig function. The initialization of the neural network is to use the init function in the toolbox to return the weights and errors of the neural network. A trainable feedforward network is established using the newFF function. The trainLM function is selected for the training function, while the LearngDM function is selected for the weight/threshold learning function.

\section{Fault Identification Test of Wind Turbine Gearbox based on BP Neural Network}

\subsection{BP neural network for gear fault identification}

The data in this article comes from the gear simulation failure experiment platform. The gear state includes four types: normal state, wear failure, broken tooth failure, and pitting failure. Fifty typical samples of each gear type were selected, and there are a total of 200 training samples. Table 1 shows some training samples of the BP neural network. The parameters of the neural network were set as follows. The learning rate was 0.05 ; the training steps was 100 ; the error was 0.001 .
Table 1. Training Samples of Gear Part

\begin{tabular}{|c|c|c|c|c|}
\hline $\begin{array}{l}\text { State of } \\
\text { the gear }\end{array}$ & $\begin{array}{l}\text { The } \\
\text { normal } \\
\text { state }\end{array}$ & $\begin{array}{l}\text { The } \\
\text { wear } \\
\text { failure }\end{array}$ & $\begin{array}{l}\text { Broken } \\
\text { teeth } \\
\text { failure }\end{array}$ & $\begin{array}{l}\text { Pitting } \\
\text { corrosion } \\
\text { failure }\end{array}$ \\
\hline \multirow{3}{*}{$\begin{array}{l}\text { Root } \\
\text { mean } \\
\text { square }\end{array}$} & 1.255 & 1.364 & 1.955 & 1.565 \\
\hline & 1.234 & 1.635 & 1.654 & 1.542 \\
\hline & 1.246 & 1.685 & 1.256 & 1.485 \\
\hline \multirow{3}{*}{$\begin{array}{l}\text { Crest } \\
\text { factor }\end{array}$} & 6.355 & 9.366 & 7.686 & 6.456 \\
\hline & 7.245 & 8.965 & 6.356 & 6.346 \\
\hline & 8.645 & 8.625 & 7.454 & 6.214 \\
\hline \multirow{3}{*}{$\begin{array}{l}\text { Margin } \\
\text { factor }\end{array}$} & 11.966 & 17.365 & 11.364 & 11.368 \\
\hline & 13.256 & 16.845 & 9.465 & 10.658 \\
\hline & 14.985 & 11.564 & 11.654 & 9.456 \\
\hline \multirow{3}{*}{$\begin{array}{l}\text { Form } \\
\text { factor }\end{array}$} & 2.694 & 2.684 & 2.632 & 2.644 \\
\hline & 2.642 & 2.664 & 2.354 & 2.542 \\
\hline & 2.631 & 2.691 & 2.369 & 2.486 \\
\hline \multirow{3}{*}{$\begin{array}{l}\text { Pulse } \\
\text { factor }\end{array}$} & 9.456 & 11.796 & 11.906 & 11.566 \\
\hline & 8.848 & 10.574 & 9.187 & 10.546 \\
\hline & 9.875 & 10.456 & 9.845 & 9.368 \\
\hline \multirow{3}{*}{$\begin{array}{l}\text { Kurtosis } \\
\text { factor }\end{array}$} & 4.955 & 7.362 & 4.992 & 4.864 \\
\hline & 3.646 & 6.298 & 4.224 & 4.654 \\
\hline & 3.125 & 7.859 & 3.336 & 4.248 \\
\hline
\end{tabular}

The specific identification steps are as follows. Firstly, the network parameters of the BP neural network were set; then, the gearbox data samples were trained and input into the neural network to judge the fault type. The number of iterations of rolling gear training is shown in Figure 2. It was seen that the iteration speed was relatively fast; when the number of iterations reached 14, fault identification completed, and the target was achieved in a relatively short time.

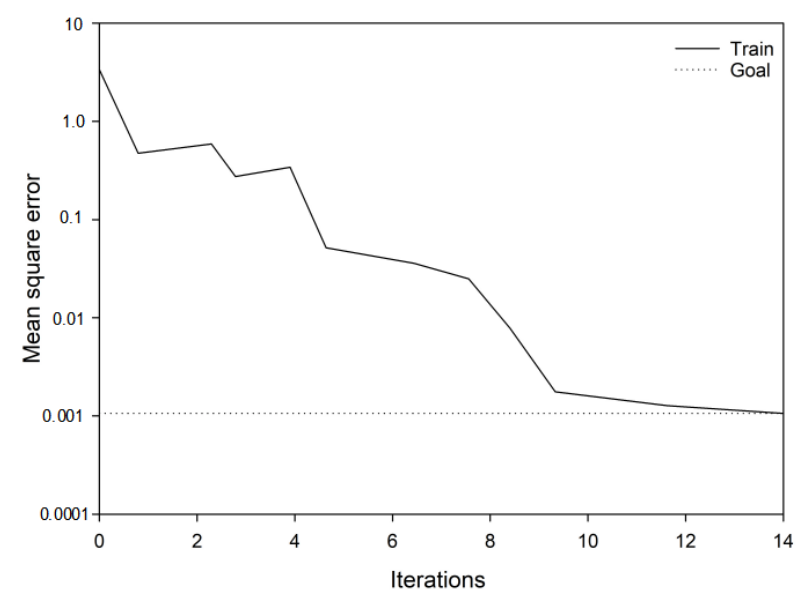

Figure 2: Number of Training Iterations

After the BP neural network was trained on the trained samples, the diagnostic target samples were obtained after the training. The diagnosis results of normal gears are shown in Table 2. Through comparison, it was found that the actual output of normal gears was very close to the ideal output $(1,0,0)$. 
Table 2. Diagnosis Results of Normal Gears

\begin{tabular}{|c|c|c|c|c|c|c|c|c|}
\hline $\begin{array}{l}\text { The } \\
\text { serial } \\
\text { number }\end{array}$ & $\begin{array}{l}\text { State of } \\
\text { the gear }\end{array}$ & $\begin{array}{l}\text { The } \\
\text { normal } \\
\text { state }\end{array}$ & $\begin{array}{l}\text { The wear } \\
\text { failure }\end{array}$ & $\begin{array}{l}\text { Broken } \\
\text { teeth } \\
\text { failure }\end{array}$ & $\begin{array}{l}\text { Pitting } \\
\text { corrosion } \\
\text { failure }\end{array}$ & $\begin{array}{l}\text { State of } \\
\text { the gear }\end{array}$ & $\begin{array}{l}\text { The actual } \\
\text { output }\end{array}$ & $\begin{array}{l}\text { The ideal } \\
\text { output }\end{array}$ \\
\hline 1 & 1.032 & 5.592 & 11.676 & 2.442 & 9.957 & 4.367 & $\begin{array}{l}(0.83022, \\
-0.24746, \\
0.00985)\end{array}$ & \multirow[t]{8}{*}{$(1,0,0)$} \\
\hline 2 & 1.034 & 4.883 & 13.052 & 2.412 & 8.740 & 5.405 & $\begin{array}{l}(1.13382, \\
-0.12813, \\
-0.10294)\end{array}$ & \\
\hline 3 & 1.036 & 5.402 & 11.401 & 2.443 & 9.707 & 5.760 & $\begin{array}{l}(0.99052, \\
0.27942, \\
0.24400)\end{array}$ & \\
\hline 4 & 1.035 & 5.685 & 11.513 & 2.422 & 9.931 & 5.882 & $\begin{array}{l}(1.25127, \\
-0.14291 \\
-0.10055)\end{array}$ & \\
\hline 5 & 1.038 & 5.685 & 11.943 & 2.454 & 10.166 & 4.725 & $\begin{array}{l}(0.82949, \\
-0.11688, \\
0.18386)\end{array}$ & \\
\hline 6 & 1.040 & 5.685 & 11.749 & 2.456 & 10.168 & 4.746 & $\begin{array}{l}(0.98254, \\
0.14625, \\
0.16489)\end{array}$ & \\
\hline 7 & 1.042 & 5.685 & 11.846 & 2.458 & 10.256 & 4.862 & $\begin{array}{l}(0.84626 \\
-0.24579 \\
0.15498)\end{array}$ & \\
\hline 8 & 1.044 & 5.685 & 11.886 & 2.462 & 10.259 & 5.246 & $\begin{array}{l}(0.95642, \\
0.15642, \\
0.16542)\end{array}$ & \\
\hline
\end{tabular}

The diagnosis results of gear wear fault are shown in Table 3. Through comparison, it was found that the actual output of gear wear fault was very close to the ideal output $(0,0,1)$.

Table 3. Diagnosis Results of Wear Fault Gears

\begin{tabular}{|c|c|c|c|c|c|c|c|c|}
\hline $\begin{array}{l}\text { The } \\
\text { serial } \\
\text { number }\end{array}$ & $\begin{array}{l}\text { State of } \\
\text { the gear }\end{array}$ & $\begin{array}{l}\text { The } \\
\text { normal } \\
\text { state }\end{array}$ & $\begin{array}{l}\text { The } \\
\text { wear } \\
\text { failure }\end{array}$ & $\begin{array}{l}\text { Broken } \\
\text { teeth } \\
\text { failure }\end{array}$ & $\begin{array}{l}\text { Pitting } \\
\text { corrosion } \\
\text { failure }\end{array}$ & $\begin{array}{l}\text { State of } \\
\text { the gear }\end{array}$ & $\begin{array}{l}\text { The actual } \\
\text { output }\end{array}$ & $\begin{array}{l}\text { The ideal } \\
\text { output }\end{array}$ \\
\hline 1 & 1.051 & 9.724 & 21.244 & 2.642 & 16.623 & 12.444 & $\begin{array}{l}(0.00573, \\
-0.00922, \\
0.82754)\end{array}$ & \multirow[t]{8}{*}{$(0,0,1)$} \\
\hline 2 & 1.050 & 8.991 & 16.119 & 2.603 & 13.817 & 9.520 & $\begin{array}{l}(-0.10450 \\
0.00530 \\
0.99213)\end{array}$ & \\
\hline 3 & 1.044 & 8.132 & 13.559 & 2.551 & 13.073 & 9.415 & $\begin{array}{l}(0.20774, \\
-0.10005, \\
1.07034)\end{array}$ & \\
\hline 4 & 1.052 & 9.190 & 16.196 & 2.649 & 14.503 & 7.149 & $\begin{array}{l}(-0.11442, \\
0.01376, \\
1.09443)\end{array}$ & \\
\hline 5 & 1.045 & 9.482 & 14.186 & 2.551 & 11.169 & 6.933 & $\begin{array}{l}(0.00497, \\
-0.02856, \\
1.14363)\end{array}$ & \\
\hline 6 & 1.046 & 9.462 & 12.458 & 2.465 & 11.235 & 6.254 & $\begin{array}{l}(0.00458, \\
-0.05645, \\
1.15645)\end{array}$ & \\
\hline 7 & 1.057 & 9.524 & 14.692 & 2.164 & 12.341 & 6.935 & $\begin{array}{l}(0.02526, \\
-0.00462, \\
0.98131)\end{array}$ & \\
\hline 8 & 1.052 & 9.654 & 15.352 & 2.695 & 12.546 & 6.153 & $\begin{array}{l}(0.00152, \\
-0.01462, \\
1.14624)\end{array}$ & \\
\hline
\end{tabular}


Through the same method, both the diagnosis results of the broken tooth fault gear and the pitting fault gear were obtained, and this article will not show them one by one.

By comparison, it was found that the actual ideal output $(0,1,0)$, and that of the pitting fault was close to the ideal output $(0,0,1)$. It was seen that the type of gear failure was achieved by setting a halfsegment threshold, which showed that it was feasible to identify the type of failure with the BP neural network. In the identification of 60 groups of fault information, 58 groups were accurately identified, and the identification accuracy rate was $96.6 \%$, which showed a good fault identification performance. output of the broken tooth fault was close to the

\subsection{BP Neural Network for Fault Identification of Rolling Bearing}

When the sample size was large enough, the accuracy of judging the fault type using the neural network was improved to a certain extent. Two hundred and forty data obtained from the experimental platform were selected as typical samples, including four states of the rolling shaft, namely, normal state, outer ring failure, inner ring failure, and ball failure, 60 training samples for each state. Table 4 shows the rolling bearing training samples of the BP neural network. The learning efficiency of the neural network was set at 0.05 , the training step length was set at 50, and the training target error was set at 0.001 .

Table 4. Training Samples of Rolling Bearing

\begin{tabular}{|l|l|l|l|l|}
\hline State of the gear & $\begin{array}{l}\text { The normal } \\
\text { state }\end{array}$ & Ball bearing failure & Inner ring fault & Outer ring fault \\
\hline \multirow{5}{*}{ Root mean square } & 1.153 & 1.233 & & \\
\cline { 2 - 5 } & 1.162 & 1.214 & 1.253 & 1.142 \\
\cline { 2 - 5 } & 1.181 & 1.113 & 1.255 & 1.143 \\
\hline Crest factor & 3.102 & 11.614 & 1.275 & 1.120 \\
\cline { 2 - 5 } & 3.227 & 7.655 & 6.374 & 5.693 \\
\cline { 2 - 5 } & 3.851 & 7.541 & 5.860 & 5.235 \\
\hline Margin factor & 8.062 & 35.242 & 8.285 & 2.863 \\
\cline { 2 - 5 } & 8.404 & 34.735 & 26.354 & 4.422 \\
\cline { 2 - 5 } & 9.182 & 34.354 & 26.505 & 3.505 \\
\hline Form factor & 2.617 & 3.662 & 35.023 & 3.952 \\
\cline { 2 - 5 } & 2.625 & 3.153 & 2.987 & 2.311 \\
\cline { 2 - 5 } & 2.681 & 3.351 & 3.053 & 2.273 \\
\hline Pulse factor & 8.144 & 27.295 & 3.442 & 2.286 \\
\cline { 2 - 5 } & 8.186 & 21.113 & 18.162 & 4.252 \\
\cline { 2 - 5 } & 9.253 & 21.176 & 16.163 & 4.254 \\
\hline Kurtosis factor & 5.555 & 25.643 & 15.274 \\
\cline { 2 - 5 } & 5.543 & 15.701 & & 3.612 \\
\cline { 2 - 5 } & 5.602 & 14.432 & \\
\hline
\end{tabular}

The number of iterations of rolling bearing training is shown in Figure 3. After 20 iterations, the

target error was reached, and the calculation speed was also fast.

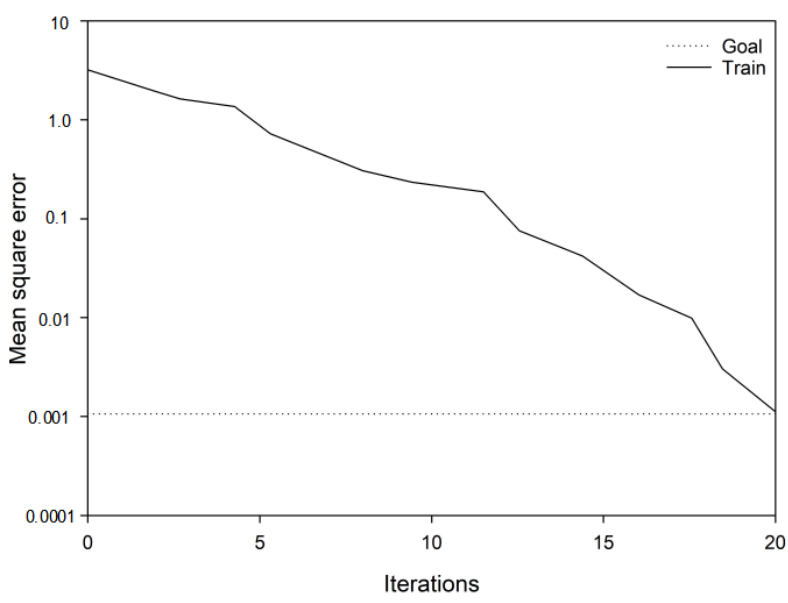

Figure 3: Number of Training Iterations 
After the BP neural network was trained on the trained samples, the diagnostic target samples were obtained. The diagnostic results of the normal rolling bearing are shown in Table 5. By comparing with the expected output, it was found that it was close to the ideal output $(0,0,0)$.

Table 5. Diagnosis Results of Normal Rolling Bearing

\begin{tabular}{|l|l|l|l|l|l|l|l|l|}
\hline $\begin{array}{l}\text { The } \\
\text { serial } \\
\text { number }\end{array}$ & $\begin{array}{l}\text { State of } \\
\text { the } \\
\text { gear }\end{array}$ & $\begin{array}{l}\text { The } \\
\text { normal } \\
\text { state }\end{array}$ & $\begin{array}{l}\text { The } \\
\text { wear } \\
\text { failure }\end{array}$ & $\begin{array}{l}\text { Broken } \\
\text { teeth } \\
\text { failure }\end{array}$ & $\begin{array}{l}\text { Pitting } \\
\text { corrosion } \\
\text { failure }\end{array}$ & $\begin{array}{l}\text { State o } \\
\text { the } \\
\text { gear }\end{array}$ & The actual output & $\begin{array}{l}\text { The ideal } \\
\text { output }\end{array}$ \\
\hline 1 & 1.263 & 8.501 & 12.611 & 2.602 & 4.771 & 4.344 & $(0.11031,-0.10003,0.21086)$ & $(0,0,0)$ \\
\hline 2 & 1.261 & 9.254 & 13.531 & 2.603 & 5.966 & 4.352 & $(-0.10015,-0.10007,0.10044)$ \\
\hline 3 & 1.282 & 8.622 & 12.642 & 2.684 & 6.845 & 4.235 & $(0.12104,-0.11061,0.11037)$ \\
\hline 4 & 1.283 & 9.581 & 13.543 & 2.312 & 6.943 & 4.562 & $(-0.00021,0.10053,0.10012)$ \\
\hline 5 & 1.281 & 8634 & 12.574 & 2.206 & 6.752 & 4.555 & $(0.11251,0.11001,-0.11163)$ \\
\hline 6 & 1.256 & 9.636 & 12.546 & 2.209 & 6.742 & 4.565 & $(0.11022,-0.10030,0.21066)$ \\
\hline 7 & 1.249 & 8.246 & 12.594 & 2.316 & 6.784 & 4.557 & $(-0.10011,-0.10066,0.10004)$ \\
\hline 8 & 1.246 & 8.698 & 13.654 & 2.264 & 6.452 & 4.542 & $(0.11244,0.11004,-0.11546)$ & \\
\hline
\end{tabular}

The diagnosis results of ball fault of rolling bearing are shown in Table 6. Through comparison, it was found that its actual output value was close to the ideal output $(0,0,1)$.

Table 6 Diagnosis Results of Ball Failure Rolling Bearing

\begin{tabular}{|l|l|l|l|l|l|l|l|l|}
\hline $\begin{array}{l}\text { The } \\
\text { serial } \\
\text { number }\end{array}$ & $\begin{array}{l}\text { State } \\
\text { of the } \\
\text { gear }\end{array}$ & $\begin{array}{l}\text { The } \\
\text { normal } \\
\text { state }\end{array}$ & $\begin{array}{l}\text { The } \\
\text { wear } \\
\text { failure }\end{array}$ & $\begin{array}{l}\text { Broken } \\
\text { teeth } \\
\text { failure }\end{array}$ & $\begin{array}{l}\text { Pitting } \\
\text { corrosion } \\
\text { failure }\end{array}$ & $\begin{array}{l}\text { State of } \\
\text { the gear }\end{array}$ & The actual output & $\begin{array}{l}\text { The ideal } \\
\text { output }\end{array}$ \\
\hline 1 & 1.116 & 15.594 & 36.611 & 3.647 & 14.211 & 20.866 & $(-0.1102,0.1013,1.0010)$ & $(0,0,1)$ \\
\hline 2 & 1.111 & 15.644 & 35.627 & 3.674 & 15.677 & 21.393 & $(-0.1201,-0.1101,0.8832)$ \\
\hline 3 & 1.185 & 13.512 & 34.592 & 3.583 & 28.721 & 20.795 & $(-0.0108,0.1004,1.0001)$ \\
\hline 4 & 1.196 & 13.683 & 38.582 & 3.375 & 16.201 & 22.226 & $(-0.1101,-0.1102,1.105)$ \\
\hline 5 & 1.183 & 13.334 & 34.671 & 3.001 & 19.047 & 19.884 & $(-0.0102,0.0524,0.9401)$ \\
\hline 6 & 1.126 & 13.242 & 35.543 & 3.153 & 18.351 & 19.543 & $(-0.0106,0.1002,1.0006)$ \\
\hline 7 & 1.185 & 13.546 & 34.268 & 3.465 & 16.552 & 20.542 & $(-0.1100,0.1011,1.0110)$ \\
\hline 8 & 1.164 & 13.862 & 35.468 & 3.698 & 15.164 & 20.692 & $(-0.0111,0.0522,0.9622)$ & \\
\hline
\end{tabular}

Through the same method, the diagnosis results of the inner ring faulty rolling bearing and the outer ring faulty rolling bearing were obtained, and this article will not show them one by one. By comparison, it was found that the actual output of inner ring fault was close to the ideal output $(0,1,0)$, while the actual output of outer ring faults was close to the ideal output $(1,0,0)$. It was seen that the type of rolling bearing failure was achieved by setting a judgment threshold, which showed that it was very feasible to identify fault types with the BP neural network. In the identification of 65 groups of fault information of rolling bearing, 62 groups were accurately identified, with an accuracy rate of about
95.3\%. According to the diagnosis results of the sample data, the BP neural network has a good accuracy rate for the fault identification of gearbox gears and rolling shafts, can meet the requirements of field application, and has a strong application value.

\section{Summary}

To sum up, this paper first gives an overview of the BP neural network model and its principle and clarifies the calculation process of the BP neural network. Secondly, the node number of the input layer, hidden layer and output layer was determined, 
and the BP neural network was built on the basis of MATLAB. Finally, the gear fault and the rolling bearing fault in the gearbox of wind power generation were identified by the BP neural network. The results verify the feasibility of the $\mathrm{BP}$ neural network technology in identifying gearbox faults.

\section{References}

[1] Li H, Hu YG, Li Y, et al. "Research review on status monitoring and Fault diagnosis of highpower grid-connected wind turbines," Electric Power Automation Equipment, 2016, 36(001):6-16.

[2] Diao Y L. "Operation and maintenance of wind turbines in electrical equipment of wind power plants," Engineering Technology Research, 2017.

[3] Zhang X L. "Research on online Monitoring and Diagnosis System of Wind Turbine," Electronic World, 2016, 000(014):126-126.

[4] Long X F, Yang P, Guo H X, et al. "Overview of fault diagnosis methods for large-scale wind turbine," Power Grid Technology, 2017, 041(011):3480-3491.
[5] Chen F, Wei Z N, Zhang X L, et al. "Reliability Modeling and Application of Wind farm with Wind Speed and Wind turbine Fault Correlation," Chinese Journal of Electrical Engineering, 2016, 36(11):2900-2908.

[6] Jin X H, Sun Y, Shan J H, et al. "Review of wind turbine Fault diagnosis and Prediction Technology," Chinese Journal of Instrumentation, 2017, 38(005):1041-1053.

[7] Jin T Y, Ren X M. "Application of Improved Limit Learning Machine in fault diagnosis of Fan Gear," Sci-tech \& Economy Guide, 2017, 000(025): P.59-59.

[8] Xiao L J, Xie Y, Wang J, et al. "Application of multi-sensor fusion based on evidence theory and support vector machine in fault diagnosis of fan gear," Sci-tech Wind, 2017, 000(009):183,185.

[9] Liu Y F, Huang X X, Song $H$, et al. "Fault prediction of Wind Turbine Gearbox in wind power Generation system," Computer Simulation, 2019, 036(003):124-127,146.

[10] Wen X. "Intelligent fault diagnosis Technology: MATLAB Application," Beijing University of Aeronautics and Astronautics Press, 2015. 